\title{
Perencanaan Kinerja Komite Penjamin Mutu BPSDM Provinsi Jawa Barat
}

\author{
Bella Ayu Pratiwi a * \\ ${ }^{a}$ Lembaga Administrasi Negara (LAN), Jakarta, Indonesia
}

\section{INFORMASI ARTIKEL}

\section{Article history:}

Dikirim tanggal: 09 Januari 2019

Revisi pertama tanggal: 12 Maret 2019

Diterima tanggal: 18 April 2019

Tersedia online tanggal: 26 April 2019

Keywords: performance planning, quality, quality assurance committe, government training institution

\begin{abstract}
National Institute of Public Administration command to all of the Government training institution to form The independent team of Quality Assurance Committee. The aim of this study is to describe the performance planning model of the quality assurance committee team based on the quality model from Juran's Trilogy. A qualitative approach was used in this study. The result of this study proves that the QAC Team of BPSDM West Java Province has carried out performance planning (Bacal) according to the stages. The model used as a reference is the quality model of the Juran's Trilogy. The model is almost the same as Robert Bacal's performance planning. However, the disadvantage is that there are no performance indicators that shows the benefits and impact of implementating quality assurance.
\end{abstract}

\section{INTISARI}

Lembaga Administrasi Negara menginstruksikan kepada seluruh lembaga diklat pemerintah untuk membentuk Tim Komite Penjamin Mutu yang bersifat independen. Penelitian ini bertujuan untuk mendeskripsikan model perencanaan kinerja Tim Komite Penjamin Mutu BPSDM Provinsi Jawa Barat. Pendekatan penelitian ini ialah kualitatif. Hasil penelitian ini membuktikan bahwa Tim KPM BPSDM Provinsi Jawa Barat telah melakukan perencanaan kinerja (Bacal) sesuai dengan tahapannya. Adapun model yang dijadikan sebagai acuan, yakni model mutu Trilogi Juran. Model tersebut nyaris sama dengan perencanaan kinerja Robert Bacal. Namun demikian yang menjadi kekurangannya ialah belum adanya indikator kinerja yang menampilkan benefit dan impact atas pelaksanaan penjaminan mutu

2019 FIA UB. All rights reserved.

\section{Pendahuluan}

Penelitian ini dilatarbelakangi oleh instruksi Kepala LAN kepada Lembaga Diklat Pemerintah untuk membentuk Tim Komite Penjamin Mutu sebagaimana yang terkandung dalam Peraturan Kepala LAN Nomor 25 Tahun 2015. Penjaminan mutu atau yang dalam bahwa Inggrisnya dikenal dengan sebutan Quality Assurance merupakan sebuah pendekatan sistematis untuk mengejar mutu dengan tujuan agar tercapai kesesuaian produk, jasa dan proses dengan standar yang telah ditentukan
(Jabnoun, 2004). Berdasarkan konsep Quality Assurance tersebut terlihat bahwa jaminan mutu penting untuk menjadi perhatian agar produk atau jasa yang dihasilkan sesuai dengan standar yang telah ditentukan. Tim Komite Penjamin Mutu digadang sebagai free thinker yang independen.

Namun secara empiris banyak lembaga diklat pemerintah hanya sekedar membentuk Tim KPM sebagai syarat pengajuan akreditasi. Hal tersebut terlihat dalam hasil monitoring dan evaluasi yang dilakukan oleh Tunsiah (2017) terhadap delapan lembaga diklat 
pemerintah daerah, dimana sebagian besar lembaga diklat masih sebatas memiliki SK Pengangkatan KPM.

Tabel 1 Checklist Unsur Penilaian

Komite Penjamin Mutu

\begin{tabular}{|c|c|c|c|c|c|}
\hline \multirow[b]{2}{*}{ No } & \multirow[b]{2}{*}{$\begin{array}{l}\text { Lokus Monitoing } \\
\text { Evaluasi }\end{array}$} & \multicolumn{4}{|c|}{ Unsur yang ditanyakan } \\
\hline & & $\begin{array}{c}\text { Ketersediaan } \\
\text { SK } \\
\text { Pengesahan } \\
\text { KPM }\end{array}$ & $\begin{array}{c}\text { Tindak } \\
\text { Lanjut } \\
\text { KPM }\end{array}$ & $\begin{array}{c}\text { Ketersediaan } \\
\text { Pedoman } \\
\text { Penyelenggaraan }\end{array}$ & $\begin{array}{c}\text { Ketersediaan } \\
\text { Instrumen } \\
\text { Evaluasi }\end{array}$ \\
\hline 1 & $\begin{array}{l}\text { Badan } \\
\text { Pengembangan } \\
\text { Sumber Daya } \\
\text { Manusia } \\
\text { (BPSDM) } \\
\text { Provinsi } \\
\text { Lampung }\end{array}$ & $\sqrt{ }$ & - & - & - \\
\hline 2 & $\begin{array}{l}\text { BPSDM Provinsi } \\
\text { Kalimantan } \\
\text { Timur }\end{array}$ & $\sqrt{ }$ & - & - & - \\
\hline 3 & $\begin{array}{l}\text { BPSDM Provinsi } \\
\text { Nusa Tenggara } \\
\text { Timur }\end{array}$ & $\sqrt{ }$ & - & - & - \\
\hline 4 & $\begin{array}{l}\text { BPSDM Provinsi } \\
\text { Gorontalo }\end{array}$ & $\sqrt{ }$ & - & - & - \\
\hline 5 & $\begin{array}{l}\text { BPSDM } \\
\text { Kabupaten } \\
\text { Sragen }\end{array}$ & $\sqrt{ }$ & - & - & - \\
\hline 6 & $\begin{array}{l}\text { PKP2A 1 LAN } \\
\text { Jatinangor }\end{array}$ & $\sqrt{ }$ & - & - & - \\
\hline 7 & $\begin{array}{l}\text { BPSDM Provinsi } \\
\text { Riau }\end{array}$ & $\sqrt{ }$ & - & - & - \\
\hline 8 & $\begin{array}{l}\text { BPSDM Provinsi } \\
\text { Sulawesi Selatan }\end{array}$ & $\sqrt{ }$ & - & - & - \\
\hline
\end{tabular}

Sumber: Hasil analisis, 2018

Selain itu juga pembentukkan Tim KPM masih mengacu pada Peraturan tentang Akreditasi, belum ada payung hukum khusus bagi Tim KPM. Persoalan normatif terkait payung hukum keberadaan Komite Penjamin Mutu secara lebih mendetail menyebabkan tidak optimalnya fungsi Tim KPM yang diharapkan dapat memberikan laporan akurat sebagai dasar dalam monitoring dan evaluasi penyelenggaraan diklat yang dilakukan oleh pihak eksternal. Sehingga secara lebih lanjut, kelengkapan administratif Tim Komite Penjamin Mutu Lembaga Diklat akan berpengaruh kepada penilaian Akreditasi.

Disisi lain berdasarkan data pada website sipka.lan.go.id; dapat ditemukan bahwa beberapa lembaga diklat provinsi mendapat nilai akreditasi A pada beberapa program yang diajukan, salah satunya adalah Badan Pengembangan Sumber Daya Manusia Provinsi Jawa Barat sebagaimana yang tercantum pada Tabel 2 dibawah ini:

Tabel 2 Perolehan Nilai Akreditasi BPSDM Provinsi Jawa Barat

\begin{tabular}{|c|l|l|c|c|c|}
\hline No & $\begin{array}{c}\text { Nama } \\
\text { Lembaga } \\
\text { Diklat }\end{array}$ & $\begin{array}{c}\text { Nama } \\
\text { Diklat }\end{array}$ & $\begin{array}{c}\text { Nilai } \\
\text { Akreditasi }\end{array}$ & No Sertifikat & $\begin{array}{c}\text { Masa } \\
\text { Berlaku }\end{array}$ \\
\hline 1 & BPSDM & Diklat & A & - & $2017-$ \\
& Provinsi \\
Jawa Barat & $\begin{array}{l}\text { Prajabatan } \\
\text { I/II }\end{array}$ & & & $06-30$ \\
\hline
\end{tabular}

\begin{tabular}{|c|c|c|c|c|c|}
\hline No & $\begin{array}{c}\text { Nama } \\
\text { Lembaga } \\
\text { Diklat }\end{array}$ & $\begin{array}{l}\text { Nama } \\
\text { Diklat }\end{array}$ & $\begin{array}{c}\text { Nilai } \\
\text { Akreditasi }\end{array}$ & No Sertifikat & $\begin{array}{c}\text { Masa } \\
\text { Berlaku }\end{array}$ \\
\hline 2 & $\begin{array}{l}\text { BPSDM } \\
\text { Provinsi } \\
\text { Jawa Barat }\end{array}$ & $\begin{array}{l}\text { Diklat } \\
\text { Prjabatan } \\
\text { III }\end{array}$ & $\mathrm{A}$ & - & $\begin{array}{l}2017- \\
06-30\end{array}$ \\
\hline 3 & $\begin{array}{l}\text { BPSDM } \\
\text { Provinsi } \\
\text { Jawa Barat }\end{array}$ & $\begin{array}{l}\text { Diklatpim } \\
\text { Tk II }\end{array}$ & A & $759 / 1 / 9 / 2010$ & $\begin{array}{c}27 \text { juli } \\
2015\end{array}$ \\
\hline
\end{tabular}

Sumber: LAN, 2017

Tim KPM BPSDM Provinsi Jawa Barat dinilai telah memiliki kesiapan dalam melakukan penjaminan mutu. Terlihat dari hasil kerja serta nilai akreditasi BPSDM Provinsi Jawa Barat yang diperoleh. Senada dengan keterangan Kepala Sub Bidang Akreditasi, LAN RI bahwasanya BPSDM Provinsi Jawa Barat sejauh ini memiliki kelengkapan administratif yang paling baik. Kinerja Tim Komite Penjamin Mutu terlihat mulai dari perencanaan, proses penyelenggaraan hingga laporan monitoring dan evaluasi. Output atau hasil kinerja Tim Komite Penjamin Mutu juga dapat dilihat dalam bentuk laporan rutin setiap penyelenggaraan diklat yang terselenggara di BPSDM Provinsi Jawa Barat. Paradox dengan belum adanya instruksi dari LAN mengenai perencanaan kinerja komite penjamin mutu yang ada pada lembaga diklat. Penulis menganggap kondisi ini sebagai best practice dalam perencanaan kinerja komite penjamin mutu lembaga diklat. Selain itu secara akademis, perencanaan kinerja diperlukan untuk membantu terjaminnya setiap tindakan yang akan dilakukan sehingga sesuai dengan standard an target yang telah ditentukan. Oleh karenanya penulis menganggap isu ini penting pula untuk diangkat agar dapat digunakan sebagai sebuah pembelajaran bagi lembaga diklat daerah lainnya.

Dengan demikian tulisan ini berfokus pada perencanaan kinerja yang dilakukan oleh Tim KPM BPSDM Provinsi Jawa Barat berdasarkan Teori Perencanaan Kinerja dari Robert Bacal (2002). Dalam kaitannya dengan penjaminan mutu, Model Trilogi Juran digunakan untuk menganalisis pengembangan model perencanaan kinerja khusus untuk penjaminan mutu pendidikan dan pelatihan pada lembaga diklat pemerintah daerah. Trilogi Juran dipakai karena BPSDM Provinsi Jawa Barat menggunakan teori ini dalam melakukan penjaminan mutu.

Berdasarkan latar belakang tersebut, tulisan ini mencoba untuk mejawab beberapa rumusan masalah yakni: (a) Bagaimana Perencanaan Kinerja yang telah dilakukan oleh Tim KPM BPSDM Provinsi Jawa Barat; (b) Siapa Stakeholders yang terlibat dalam pembentukkan Tim KPM BPSDM Provinsi Jawa Barat; (c) Model apa yang digunakan dalam Perencanaan Kinerja KPM; dan (d) Bagaimana Potensi dan permasalahan pelaksanaan kinerja KPM BPSDM Provinsi Jawa Barat. 


\section{Teori}

\subsection{Perencanaan}

Litman (2013) menegaskan bahwa perencanaan mengacu pada proses memutuskan apa yang harus dilakukan dan bagaimana cara melakukannya. Sedangkan Le Breton \& Henning (1961) menyebutkan bahwa " $a$ plan is a predetermined course of action'. Rencana merupakan tindakan yang telah ditentukan sebelumnya sehingga sebuah rencana akan sia-sia manakala tidak ada tindak lanjutnya. Perencanaan menyangkut banyak aspek mulai dari struktur organisasi, anggaran, tenaga kerja hingga program pengendalian. Litman (2003) dalam tulisannya juga menyebutkan bahwa perencanaan merupakan sebuah kegiatan sosial dimana melibatkan banyak pihak atau stakeholders. Sehingga perencana harus siap untuk bekerja dengan orang dari berbagai latar belakang. Adapun planning stakeholders menurut Litman (2013), yakni: users, citizen, impacted residents, businesses, employes, pulic officials, Affected organizations/ interest groups and lawyer.

\subsection{Kinerja}

Kinerja merupakan sebuah konsep yang saat ini menjadi sorotan terutama pada sektor publik. Beberapa tokoh telah mencoba untuk mendefinisikan kinerja secara berbeda-beda. Yudith Hale sebagaimana dikutip oleh Amir (2015) menyebutkan bahwa "Performance imposes a perspective the questions the worth and worthiness of the efforts, the results achieved and the method used". Kinerja melibatkan sebuah perspektif yang memperhatikan pentingnya kebermaknaan dan manfaat dan upaya, hasil yang dicapai, dan metode atau cara yang digunakan. Administrasi Publik mengenal tiga fokus yang sangat berbeda dalam hal kualitas kinerja, yakni kinerja organisasi, kinerja kebijakan atau program, dan kinerja pegawai negeri sipil (Larat, 2015). Bahasan mengenai kinerja tentunya tidak terlepas dari penilaian kinerja. Penilaian kinerja digunakan untuk pengembangan karyawan dan umpan balik, perencanaan perusahaan, dokumen hukum, pemeliharaan sistem dan penelitian (Murphy \& Cleveland, 1990). Lebih lanjut Katz \& Kahn (1978) sebagaimana dikutip oleh Murphy \& Cleveland (1990:26) mencatat lima aspek lingkungan yang organisasi harus memantau dan merespon agar efektif yakni: (a) Nilai-nilai sosial; (b) Lingkungan politik dan hukum; (c) Lingkungan ekonomi/ tenaga kerja; (d) Informasi/ lingkungan teknologi; dan (e) lingkungan fisik/ geografis. Lebih lanjut Murpphy \& Cleveland (1990) menerangkan bahwa masing-masing aspek lingkungan tersebut cenderung mempengaruhi penilaian kinerja dalam beberapa cara. Namun beberapa memiliki dampak yang lebih langsung sedangkan yang lain memiliki dampak tidak langsung, tetapi tetap penting. Berdasarkan penjelasan Murphy \& Cleveland (1990), maka standar yang mendefinisikan kinerja baik dan buruk pada pekerjaan akan sangat dipengaruhi oleh aspek lingkungan. Lebih lanjut Kunarjo (2002) menyebutkan bahwa terdapat lima unsur dalam indikator kinerja, yakni: masukan (input), keluaran (output), hasil (outcome), manfaat (benefit), dan dampak (impact).

\subsection{Perencanaan Kinerja}

Perencanaan kinerja menjadi bagian penting dalam mengawali proses manajemen kinerja sebuah institusi. Perencanan Kinerja menurut Bacal (2002) merupakan suatu proses dimana karyawan dan manajer bekerja sama merencanakan apa yang harus dikerjakan karyawan pada tahun mendatang, menentukan bagaimana kinerja harus diukur, mengenali dan merencanakan cara mengatasi kendala, serta mencapai pemahaman bersama tentang pekerjaan itu. Menurut Sedarmayanti (2013) Rencana Kinerja merupakan rencana kerja tahunan sebagai penjabaran lebih lanjut perencanaan strategis, di dalamnya memuat target kinerja yang hendak dicapai dalam satu tahun mendatang dengan menunjukkan indikator kinerja kunci yang relevan. Rencana kinerja menjadi tolak ukur yang digunakan dalam menilai keberhasilan/ kegagalan penyelenggaraan pemerintahan satu periode tertentu. Sehingga Bacal (2002) menjelaskan bahwa cara terbaik mendefinisikan tujuan proses perencanaan kinerja adalah dengan menentukan hasilnya.

Sebagai sebuah entitas yang baru dibentuk, Tim Komite Penjamin Mutu membutuhkan sebuah forum atau wadah yang menjembataninya dengan tenaga kediklatan lainnya pada lembaga diklat. Dengan demikian perencanaan kinerja dapat memperjelas kembali mengenai tugas dan fungsi dari komite penjamin mutu sebagai pihak independen dalam lingkungan lembaga diklat. Selain itu juga, Bacal (2002) menyebutkan bahwa kegunaan dari perencanaan kinerja adalah untuk menciptakan pemahaman bersama antara karyawan dan manajer. Selanjutnya Bacal (2002) membagi perencanaan kinerja ke dalam tiga tahapan utama, yakni persiapan, pertemuan dan penutupan.

\subsection{Model Jaminan Mutu Joseph Juran}

Konsep mutu awalnya berasal dari sektor privat atau swasta yang berorientasi pada laba. Mutu diartikan sebagai sebuah standar terhadap keluaran produk yang dihasilkan suatu industri. Beberapa tokoh terkenal yang berbicara dan berkontribusi besar terhadap konsep mutu diantaranya adalah Juran (1998) menjelaskan bahwa mutu adalah "conformance to specification". Mutu merupakan suatu kesesuaian antara spesifikasi dengan ekspektasi konsumen itu sendiri.

Sedangkan Jaminan mutu memiliki kesamaan dengan asuransi, yakni kegiatan yang melibatkan pengeluaran dalam jumlah kecil untuk mengamankan 
perlindungan dari kerugian besar (Juran, 1998). Jaminan mutu dianggap sebagai konsep yang lebih baik sebab tidak hanya dilakukan pada saat proses produksi tetapi meliputi perencanaan, perancangan produksi, pengadaan bahan baku, transportasi, penyimpanan dan sebagainya (Muhandri \& Kadarisman, 2006). Penjaminan mutu (Quality Assurance) menjadi sistem mutu yang lebih komprehensif karena menyangkut kegiatan dari mulai perencanaan hingga akhir prosesnya.

Proses mutu menurut Juran merupakan proses yang panjang sejajar dengan proses manajerial dan dikenal dengan istilah "Trilogi Mutu" yang terdiri dari Perencanaan Muu, Pengendalian Mutu, dan Peningkatan Mutu (Juran, 1998). Berikut ini penjabaran mengenai Trilogi Mutu Juran:

\begin{tabular}{|c|c|c|}
\hline Quallty planning & Quallty control & Quallty Improvement \\
\hline Establlsh quallty & Evaluate actual & Prove the need \\
\hline Identify who the & Compare actua & $\begin{array}{l}\text { Establish the } \\
\text { Infrastructure }\end{array}$ \\
\hline customers are & performance with & Identify the \\
\hline DetermIne the needs & & Improvement projects \\
\hline of the customers & $\begin{array}{l}\text { Act on the } \\
\text { difference }\end{array}$ & Establlsh project \\
\hline $\begin{array}{l}\text { features that } \\
\text { respond to customers' } \\
\text { needs }\end{array}$ & & $\begin{array}{l}\text { Provide the teams } \\
\text { with resources, } \\
\text { training, and }\end{array}$ \\
\hline $\begin{array}{l}\text { Develop processes } \\
\text { able to produce the } \\
\text { product features }\end{array}$ & & $\begin{array}{l}\text { motivation to: } \\
\text { Dlagnose the causes } \\
\text { Stimulate remedles }\end{array}$ \\
\hline $\begin{array}{l}\text { Establish process } \\
\text { controls: transfer } \\
\text { the plans to the } \\
\text { operating forces }\end{array}$ & & $\begin{array}{l}\text { Establish controls to } \\
\text { hold the gains }\end{array}$ \\
\hline
\end{tabular}

Gambar 1 The Quality Trilogy

Sumber: Juran, 1998

\section{Metode Penelitian}

Penelitian ini menggunakan pendekatan kualitatif dengan jenis penelitian deskriptif. Adapun lokus dari penelitian ini terdiri dari dua lokus utama, yaitu Pusat P3D LAN dan Kantor KPM BPSDM Provinsi Jawa Barat. Fokus Penelitian ini, yakni sebagai berikut:

a) Perencanaan Kinerja yang telah dilakukan oleh Tim KPM BPSDM Provinsi Jawa Barat;

b) Stakeholders yang terlibat dalam pembentukkan Tim KPM BPSDM Provinsi Jawa Barat;

c) Model yang digunakan dalam Perencanaan Kinerja KPM; dan

d) Potensi dan permasalahan pelaksanaan kinerja KPM BPSDM Provinsi Jawa Barat.

Data dikumpulkan melalui wawancara mendalam dan studi literatur. Selanjutnya penentuan informan menggunakan mekanisme disengaja atau pusposive sampling. Sebelum melakukan penelitian, peneliti menetapkan kriteria tertentu yang harus dipenuhi oleh orang yang akan menjadi informan kunci. Dasar utama penentuan informan adalah penguasaan informasi dan data yang dibutuhkan. Berdasarkan hal tersebut informan kunci dalam penelitian ini adalah Kepala Bidang Akreditasi dan SIDA Pusat Pembinaan Program dan Pembinaan Diklat Lembaga Administrasi Negara dan Kepala Badan Pengembangan Sumber Daya Manusia Provinsi Jawa Barat. Analisis data pada penelitian ini menggunakan model Analisis Data Interaktif dari Miles, Huberman, \& Saldana (2014) yang meliputi tiga alur kegiatan yakni: a) Kondensasi Data; b) Penyajian Data; dan c) Penarikan Kesimpulan.

\section{Hasil Penelitian dan Pembahasan}

Badan Pengembangan Sumber Daya Manusia Provinsi Jawa Barat yang untuk selanjutnya disingkat menjadi BPSDM Provinsi Jawa Barat, terletak di Kota Cimahi memiliki wilayah kerja yang cukup luas yakni mencakup wilayah Jawa Barat seluruhnya. Disisi lain jumlah Tim Komite Penjamin Mutu yang hanya berjumlah lima orang bertanggungjawab untuk memastikan penyelenggaraan diklat berjalan sesuai standar. Ditambah lagi dengan bentuk instrumen yang masih manual. Sehingga dibutuhkan sebuah Perencanaan Kinerja yang cukup matang agar tujuan dari pembentukkan Komite Penjamin Mutu dapat terlaksana.

\subsection{Perencanaan Kinerja yang telah Dilakukan Tim KPM BPSDM Provinsi Jawa Barat}

Berdasarkan hasil wawancara yang telah dilakukan oleh peneliti, Tim KPM BPSDM Provinsi Jawa Barat, melaksanakan tugas dan tanggungjawabnya. dengan terlebih dahulu melakukan mempelajari tentang hal -hal yang berkaitan dengan penjaminan mutu penyelenggaraan diklat. Dari hasil penelitian ditemukan bahwa secara tidak langsung KPM BPSDM Provinsi Jawa Barat telah melakukan tiga tahapan perencanaan kinerja yang diusung oleh Robert Bacal. Hal tersebut tidak lain karena Tahapan Perencanaan Kinerja (Robert Bacal) hampir menyerupai model trilogi mutu (Joseph Juran). Berikut ini penjabaran tahapan perencanaan kinerja (Robert Bacal) yang telah ataupun belum dilaksanakan oleh Tim KPM BPSDM Provinsi Jawa Barat:

\subsubsection{Tahapan Persiapan}

Pada tahapan ini pengelola diklat bersama-sama dengan elemen lainnya termasuk tim komite penjamin mutu secara bersama-sama memahami kembali mengenai tujuan keberadaan lembaga diklat, tugas pokok dan fungsinya masing-masing dan jika ada dapat juga mempelajari hasil evaluasi kinerja pada tahun sebelumnya. Pada tahapan ini tiap komponen dapat mengkaji ulang mengenai infromasi-informasi apa saja yang relevan berkaitan dengan penyelenggaraan dan standar mutu diklat. Dari hasil penelitian ditemukan 
bahwa, terdapat diskusi antara Kepala BPSDM dengan beberapa calon anggota KPM sebelum terjun ke lapangan. Diskusi tersebut berisi tentang kondisi lembaga diklat hingga perkembangan mutu diklat saat ini. Tahapan ini penting karena pada tahapan ini tiap komponen dapat mengkaji ulang mengenai infromasiinformasi apa saja yang relevan berkaitan dengan penyelenggaraan dan standar mutu diklat. Peneliti juga menemukan informasi bahwa, Tim KPM BPSDM Provisi Jawa Barat melakukan persiapan dengan cara mempelajari beberapa peraturan terkait penyelenggaraan diklat seperti peraturan kepala LAN dan juga yang terkait dengan penjaminan mutu dengan mempelajari dokumendokumen ISO.

\subsubsection{Tahapan Pertemuan}

Tahapan pertemuan dilalui oleh KPM BPSDM Provinsi Jawa Barat dengan melakukan pertemuan dengan Kepala BPSDM Provinsi Jawa Barat beserta jajarannya untuk dapat bekerja sama merencanakan penjaminan mutu dengan Tim Komite Penjamin Mutu. Dari hasil penelitian ditemukan bahwa setiap tahunnya, semua anggota KPM mengadakan rapat dengan kepala BPSDM untuk melakukan evaluasi kinerja sekaligus membahas mengenai fokus pekerjaan pada satu tahun kedepan. Hal tersebut sejalan dengan yang diungkapkan oleh Bacal yakni tahapan ini merupakan jantung perencanaan kinerja dimana setiap komponen bertemu untuk duduk bersama mendiskusikan pekerjaan untuk tahun yang akan datang.

Pada tahapan ini, baik pengelola maupun komponen lain bersama-sama menentukan tujuan lembaga diklat pada tahun mendatang. Beberapa hal yang dihasilkan pada tahapan ini berdasarkan analisis peneliti yakni:

a) Tujuan penjaminan mutu;

b) Tugas dan tangungjawab masing-masing anggota KPM;

c) Cara atau instrumen yang digunakan untuk mencapai tujuan; dan

d) Fokus khusus terhadap tujuan.

Lebih lanjut lagi, Bacal juga menyebutkan bahwa perlu adanya kriteria atau indikator keberhasilan dari kinerja komite penjamin mutu. Standar keberhasilan tersebut harus spesifik, dapat dicapai dengan upaya yang cukup dan sebisa mungkin bersifat objektif dan dapat diukur (Bacal, 2002).

Selain itu juga Bacal menjelaskan bahwa pada tahap pertemuan juga harus ada momen untuk mendiskusikan mengenai kendala-kendala dan bantuan yang diperlukan serta diskusi mengenai prioritas dan kewenangan. Hal ini ada dan terlaksana pada KPM BPSDM Provinsi Jawa Barat.

\subsubsection{Tahapan Evaluasi}

Berdasarkan hasil penelitian ditemukan bahwa Tim Komite Penjamin Mutu melakukan evaluasi dalam bentuk laporan tahunan. Disamping itu juga, Tim KPM melakukan komunikasi setiap bulannya melalui rapat dengan pengelola diklat. Bahkan jika ada kondisi yang mendesak, Tim KPM dapat menghubungi dan melaporkan langsung kepada Kepala BPSDM sehingga dapat ditangani secara lebih cepat.

Berdasarkan teori perencanaan kinerja Robert Bacal, Tim KPM BPSDM Provinsi Jawa Barat telah melakukan ketiga tahapan tersebut. Selain itu juga pada Tabel 3 terlihat bahwa Tim Komite Penjamin Mutu telah memiliki jobdesk yang cukup jelas. Meskipun pada saat dilapangan, Tim KPM terjun secara bersama-sama, tetapi kacamata yang dipakai berbeda-beda sesuai dengan uraian tugasnya.

Sebagai catatan tambahan dari hasil anlisis peneliti, setidaknya dalam perencanaan kinerja KPM perlu ada unsur dalam indikator kinerja. Sebab peneliti belum menemukan indikator kinerja dalam proses penjaminan mutu. Sebagaimana yang disebutkan oleh Kunarjo (2002) bahwa terdapat lima unsur dalam indikator kinerja yakni: masukan (input), keluaran (output), hasil (outcome), manfaat (benefit), dan dampak (impact). Berikut ini contoh sederhana dari indikator kinerja KPM.

Tabel 3 Indikator Kinerja KPM

\begin{tabular}{|c|c|c|c|c|c|c|}
\hline & Input & & Output & Outcome & Benefit & Impact \\
\hline $\begin{array}{l}\text { a) } \\
\text { b) } \\
\text { c) }\end{array}$ & $\begin{array}{l}\text { SK tentang } \\
\text { KPM } \\
\text { Anggaran } \\
\text { Dukungan } \\
\text { Sarana dan } \\
\text { Prasarana }\end{array}$ & a) & $\begin{array}{l}\text { Penjaminan } \\
\text { mutu sesuai } \\
\text { dengan SOP } \\
\text { Observasi dan } \\
\text { Monev } \\
\text { dilaksanakan } \\
\text { berdasarkan } \\
\text { Instrumen } \\
\text { Kerja }\end{array}$ & $\begin{array}{l}\text { Laporan } \\
\text { Penjaminan } \\
\text { Mutu }\end{array}$ & $\begin{array}{l}\text { a) Penyelenggaraan } \\
\text { Diklat berjalan } \\
\text { sesuai standar } \\
\text { b) Menurunnya } \\
\text { angka pelanggaran } \\
\text { diklat } \\
\text { c) Peningkatan nilai } \\
\text { akreditasi }\end{array}$ & $\begin{array}{l}\text { a) Kualitas } \\
\text { lulusan } \\
\text { diklat } \\
\text { semakin } \\
\text { baik } \\
\text { b) ASN yang } \\
\text { mampu } \\
\text { bersaing } \\
\text { secara } \\
\text { Global }\end{array}$ \\
\hline
\end{tabular}

Sumber: Hasil analisis, 2018

Seperti yang dikatakan Sedarmayanti (2013) Rencana Kinerja merupakan rencana kerja tahunan sebagai penjabaran lebih lanjut perencanaan strategis, didalamnya memuat target kinerja yang hendak dicapai dalam satu tahun mendatang dengan menunjukkan indikator kinerja kunci yang relevan. Rencana kinerja menjadi tolak ukur yang digunakan dalam menilai keberhasilan/ kegagalan penyelenggaraan pemerintahan satu periode tertentu. Sehingga sebagai sebuah entitas yang baru dibentuk, Tim Komite Penjamin Mutu membutuhkan sebuah forum atau wadah yang menjembataninya dengan tenaga kediklatan lainnya pada lembaga diklat.

Berdasarkan hasil penelitian, ditemukan bahwa Tim KPM BPSDM Provinsi Jawa Barat telah melakukan perencanaan kinerja (Bacal) sesuai dengan tahapannya. Hal tersebut dikarenakan, Tim KPM menggunakan 
proses dan tahapan ISO sebagai role model dalam penjaminan mutu. Adapun model yang dijadikan sebagai acuan, yakni model mutu Trilogi Juran. Model tersebut nyaris sama dengan perencanaan kinerja Robert Bacal. Namun demikian yang menjadi kekurangannya ialah belum adanya indikator kinerja yang menampilkan benefit dan impact atas pelaksanaan penjaminan mutu. Oleh karena itu peneliti mencoba untuk memberikan rekomendasi indikator kinerja untuk Tim KPM seperti yang tergambar pada Tabel 3.

\subsection{Stakeholders yang Terlibat dalam Pembentukkan Komite Penjamin Mutu}

Pembentukkan Tim Komite Penjamin Mutu merupakan salah satu dari bagian perencanaan kediklatan bagi lembaga diklat pemerintah. Hal tersebut dikarenakan sesuai dengan instruksi Kepala Lembaga Administrasi Negara yang tertuang dalam Peraturan Kepala LAN Nomor 25 Tahun 2015 menyatakan bahwa Lembaga Diklat terkareditasi harus memiliki Tim Komite Penjamin Mutu. Secara teoritis, perencanaan merupakan sebuah kegiatan sosial dimana melibatkan banyak pihak atau stakeholders (Litman, 2013). Dengan demikian ada yang dinamakan sebagai Planning Stakeholders seperti yang disebutkan oleh Litman (2003) yakni users, citizen, impacted residents, businesses, employes, pulic officials, affected organizations/ interest groups and lawyer. Dari hasil penelitian diketahui bahwa stakeholders yang terlibat dalam pembentukkan Tim Komite Penjamin Mutu BPSDM Provinsi Jawa Barat mancakup seluruh pengelola diklat, mulai dari Kepala Badan, Kepala Bidang hingga staf di semua bidang.

Walaupun pembentukkan Tim KPM menjadi perhatian khusus lembaga diklat pada saat LAN menginstruksikan Pembentukkan Komite Penjamin Mutu melalui Peraturan Kepala LAN Nomor 25 Tahun 2015 tentang Akreditasi, namun masih terkendala keterangan lebih lanjut mengenai pembentukan komite penjamin mutu. Secara sederhana P3D LAN baru menyampaikan jumlah minimal dan maksimal, kriteria indepensi dan gambaran singkat mengenai tugas KPM. Sehingga terjadi ketidakkejelasan mengenai bagaimana proses pembentukkan komite penjamin mutu sesuai standar.

Peneliti juga menemukan bahwa dalam kasus pembentukkan Tim Komite Penjamin Mutu BPSDM Provinsi Jawa Barat, Kepala BPSDM memiliki peran yang cukup besar. Adanya perhatian serius dari Kepala BPSDM beserta jajarannya pada saat pembentukkan Tim KPM. Sehingga kualitas kinerja Tim KPM cukup baik. Sedangkan dari sisi Planning Stakeholders (Litman, 2013); BPSDM Provinsi Jawa Barat baru melibatkan stakeholders internal dalam pembentukkan Tim KPM.

\subsection{Model yang Digunakan dalam Pelaksanaan Kinerja Komite Penjamin Mutu}

Tim Komite Penjamin Mutu lembaga diklat berdasarakan peraturan kepala LAN tentang akreditasi, berjumlah ganjil terdiri dari minimal tiga orang dan maksimal lima orang. Sedangkan Tim KPM BPSDM Provinsi Jawa Barat berjumlah lima orang. Disisi lain ruang lingkup kerja Tim KPM BPSDM provinsi Jawa Barat cukup luas. Tidak hanya yang terselenggara di BPSDM Provinsi Jawa Barat tetapi juga yang terselenggara di kabupaten dan kota di Jawa Barat. Tidak hanya penyelanggaraan diklat yang berasal dari anggaran APBD tetapi juga yang berasal dari daerah atau instansi lain. Sehingga dapat dikatakan wilayah kerja komite penjamin mutu BPSDM Provinsi Jawa Barat cukup luas. Oleh karena itu model dalam pelaksanaan penjaminan mutu menjadi bagian penting mengingat intensitas kegiatan pengembangan Kompetensi SDM Aparatur di BPSDM Provinsi Jawa Barat cukup tinggi. Pada Tahun 2017 saja telah terselenggara 117 diklat dengan berbagai jenis sebagaimana yang terlihat pada Tabel 3, sehingga dibutuhkan sebuah cara efektif untuk melakukan penjaminan mutu.

Informasi yang diperoleh dari hasil wawancara, dua orang anggota KPM BPSDM Provinsi Jawa Barat pernah terlibat dalam Sertifikasi ISO 9000. Bahkan Bapak ENS sudah mengikuti beberapa kali diklat terkait dengan ISO. Sehingga pelaksanaan penjaminan mutu sebagian besar mengikuti proses yang berlaku pada kegiatan sertifikasi ISO. Hal itu terlihat dari bentuk instrumen yang dibuat oleh Tim KPM serta model jaminan mutu yang digunakan. Model yang digunakan oleh Tim Komite Penjamin Mutu dalam melakukan penjaminan mutu diklat yakni dengan menggunakan Trilogi Mutu yang diperkenalkan oleh Juran, yakni Perencanaan Mutu, Pengendalian Mutu dan Peningkatan Mutu.

Secara teoritis model mutu dengan konsep yang diusung oleh Juran memandu Tim KPM dalam melakukan penjaminan mutu dengan memastikan kesesuaian antara standar diklat yang dikeluarkan oleh LAN dengan pelaksanaan diklat yang terselenggara di BPSDM Provinsi Jawa Barat. Terlihat dari bentuk Laporan Penjaminan Mutu yang telah terbagi dalam tiga bagian utama. Namun demikian, mengacu pada pandangan Juran tentang trilogi mutu, maka kita akan mendapati celah kekurangan yang secara tidak sadar menjadi sebuah kelebihan bagi Tim KPM BPSDM Provinsi Jawa Barat. Yakni keterlibatan Kepala Badan dalam perencanaan hingga pemberian keluasaan yang luas bagi tim komite penjamin mutu dalam melakukan penjaminan mutu. 
Penjaminan Mutu Lembaga Diklat sebagai sebuah proses yang tidak berkesudahan dalam menjaga dan meningkatkan mutu diklat membutuhkan sebuah perencanaan. Proses mutu menurut Juran merupakan proses yang panjang sejajar dengan proses manajerial dan dikenal dengan istilah "Trilogi Mutu" yang terdiri dari Perencanaan Mutu, Pengendalian Mutu dan Peningkatan Mutu (Juran, 1998).

\subsubsection{Perencanaan Mutu Penyelenggaraan Diklat}

Tahapan ini merupakan tahapan awal pada saat Tim KPM merencanakan kinerjanya dalam satu tahun kedepan yang terdiri dari:

a) Menetapkan Sasaran Mutu

Tim KPM BPSDM Provinsi Jawa Barat setiap tahunnya menyusun fokus guna peningkatan mutu diklat. Misalnya pada Tahun 2017 penjaminan mutu difokuskan pada pelaksanaan fungsi dan peran dari Widyaiswara. Sedangkan pada Tahun 2018 fokusnya ialah perbaikan dan sinergitas data dengan SIDA/ SIPKA yang ada di LAN.

b) Mengidentifikasi siapa pelanggannya/ stakeholdersnya

Komite Penjamin Mutu mengidetifikasi stakeholdersnya berdasarkan entitas yang berinteraksi secara langsung dalam penyelenggaraan pendidikan dan pelatihan. Bukan hanya peserta diklat tetapi juga pengelola, penyelenggara hingga petugas yang membantu seperti officeboy dan penyedia cattering .

c) Menentukan kebutuhan pelanggan

Pelanggan dalam penyelenggaraan diklat diartikan sebagai peserta diklat dan juga instansi yang mengirim peserta diklat. Peserta diklat memiliki kebutuhan yang berbeda dengan instansi pengirimnya. Sehingga cara yang tepat dalam menentukan kebutuhan pelanggan yakni dengan mengkategorikan terlebih dahulu pelanggannya kemudian melakukan inventarisasi apa saja yang menjadi kebutuhannya.

d) Mengembangkan fitur produk yang menanggapi kebutuhan pelanggan

Fitur produk yakni fasilitas diklat hingga mutu pengajaran yang diberikan widyaiswara. Tim KPM mempelajari Dokumen Standar Eksternal yang terkait dengan penjaminan mutu yakni Undang-Undang Nomor 25 Tahun 2008 Tentang Pelayanan Publik dan Peraturan Kepala LAN Nomor 25 Tahun 2015 tentang Akreditasi serta beberapa peraturan lain terkait penyelenggaraan diklat. Dari sana, Tim KPM mulai merancang cara atau metode yang digunakan yakni melalui monev, instrument yang akan digunakan hingga pada bentuk laporan akhirnya. Berdasarkan Dokumen laporan KPM ditemukan bahwa komponen yang menjadi dasar pelaksanaan monev penjaminan mutu terdiri dari Komponen Program Diklat,
Komponen Tenaga Kediklatan dan Komponen Sarana dan Prasarana.

e) Mengembangkan proses yang mampu menghasilkan fitur produk

Pengembangan proses ini dilakukan dengan cara koordinasi antara pengelola, penyelenggara, widyaiswara dan komite penjamin mutu.

\subsubsection{Pengendalian Mutu Penyelenggaraan Diklat}

Tahapan kedua, yakni tahapan pengendalian mutu diterjemahkan sebagai sebuah kegiatan observasi, monitoring dan evaluasi pada penyelenggaraan diklat pola APBD dan Pola kerjasama sebagaiaman yang tercantum dalam Dokumen Laporan Tim KPM.

a) Mengevaluasi kinerja aktual

Berdasarkan hasil wawancara, pada Pola APBD yang pelaksanaannya dilakukan di BPSDM Provinsi Jawa Barat maka Tim KPM melakukan observasi secara langsung dengan membagi tugas antar tim. Namun pada pola kerjasama Tim KPM memilih secara random penyelenggaraan-penyelenggaraan diklat yang terselenggara diluar BPSDM Provinsi Jawa Barat. Hal tersebut dikarenakan masih terbatasnya anggaran, dan sumber daya.

b) Membandingkan kinerja aktual dengan sasaran kualitas

Berdasarkan hasil wawancara diperoleh informasi bahwa kegiatan observasi Tim KPM dilakukan bersama-sama dengan evaluator institusi cq. Sub Bidang Pengelolaan Kelembagaan dan Tenaga Pengembangan Kompetensi serta dengan Auditor Internal Sistem Manajemen Mutu/ SMM ISO 9001:2015 BPSDM Provinsi Jawa Barat. Kegiatan observasi, monitoring dan evaluasi dilakukan dengan menggunakan instrumen yang telah disusun oleh tim KPM.

c) Bertindak atas perbedaannya

Kemudian Tim KPM membuat catatan atas kejadian lapangan yang terjadi. Jika ada kesalahan yang dapat diperbaiki langsung maka, Tim KPM melakukan perbaikan langsung, namun jika membutuhkan waktu maka biasanya Tim KPM melaporkan terlebih dahulu kepada Kepala Badan Ataupun pengelola yang bertanggungjawab.

\subsubsection{Peningkatan Mutu Penyelenggaraan Diklat}

Pada tahapan ketiga ini dalam rangka peningkatan metode penjaminan mutu melalui cara antara lain sebagai berikut:

a) Buktikan kebutuhannya

Tim KPM dituntut untuk memiliki kapasitas dalam menjelaskan kepada Kepala Badan mengenai hasil temuannya pada saat observasi dan monev melalui catatan dan dokumentasi serta. Selain itu juga Tim KPM membuat laporan singkat setiap pada setiap 
observasi yang dilakukannya. Sehingga saran dan masukkan atas kegiatan penjaminan mutu dapat di respon dengan segera.

b) Menyediakan tim dengan sumber daya (pelatihan dan motivasi untuk mendiagnosa penyebabnya, merangsang perbaikan)

Tim KPM BPSDM Provinsi Jawa Barat menyerap informasi dari pihak-pihak terkait yang melakukan studi banding ke BPSDM Provinsi Jawa Barat, dan juga menyerap informasi dari Auditor eksternal (Surveilance) dari Lembaga Sertifikasi SMM ISO. Selain itu juga Tim KPM melakukan beberapa kunjungan kerja ke Lembaga Administrasi Negara dalam rangka peningkatan metode penjaminan mutu.

\subsection{Potensi dan Permasalahan Pelaksanaan Kinerja KPM BPSDM Provinsi Jawa Barat}

Tim Komite Penjamin Mutu BPSDM Provinsi Jawa Barat memiliki beberapa potensi yakni berperan objektif, memiliki kesadaran akan mutu diklat, dan merupakan 'alumni pejabat' di BPSDM Provinsi Jawa Barat. Dari hasil wawancara diperoleh informasi bahwa Tim KPM yang merupakan alumni pejabat di BPSDM Provinsi Jawa Barat memiliki 'ambisi' untuk dapat meningkatkan mutu penyelenggaraan di BPSDM Provinsi Jawa Barat. Hal tesebut menjadi salah satu potensi pelaksanaan kinerja komite penjamin mutu.

Adapun beberapa permasalahan yang menjadi kendala Tim KPM BPSDM Provinsi Jawa Barat dalam melakukan penjaminan mutu diklat dari hasil penelitian, yakni keterbatasan jumlah anggota KPM yang tidak sebanding dengan intensitas penyelenggaraan diklat, instrumen yang bersifat manual dan monev yang bersifat random sampling.

Sedangkan untuk melihat potensi dan permasalahan pelaksanaan kinerja komite penjamin mutu BPSDM Provinsi Jawa Barat, penelitian menggunakan teori kinerja yang di usung oleh Kats dan Kahn yang dikutip oleh Murphy and Cleveland (1990) dimana terdapat lima aspek lingkungan yang organisasi harus memantau dan merespon agar efektif, antara lain sebagai berikut:

a) Nilai-nilai Sosial

KPM BPSDM Provinsi Jawa Barat memiliki rasa memiliki terhadap BPSDM. Hal tersebut dilatarbelakangi oleh pengalaman mereka yang sudah pernah terlibat dan menjabat di BPSDM Provinsi Jawa Barat. Hal ini menjadi nilai positif terhadap kinerja KPM.

b) Lingkungan Politik dan Hukum

KPM Provinsi Jawa Barat memiliki dasar hukum yakni SK Kepala Badan, bahkan pada Tahun 2018 sedang dalam proses untuk mengesahkan SK Gubernur. Salah satu hal yang menjadi kendala dalam operasional penjaminan mutu diklat yakni terkait anggaran. Dengan diperjuangkannya SK Gubernur untuk Tim KPM maka posisi Tim KPM dapat lebih kuat sehingga alokasi anggaran dapat lebih dimaksimalkan. Hal ini menjadi nilai positif terhadap kinerja KPM.

c) Lingkungan Tenaga Kerja

Formasi Tim KPM yang berjumlah lima orang menjadi tantangan besar untuk menjamin mutu diklat yang intensitas penyelenggaraanya cukup tinggi. Selain itu juga bentuk instrumen yang bersifat masih manual. Hal ini menjadi nilai negative terhadap kinerja KPM.

d) Informasi/ Lingkungan Teknologi

Salah satu anggota tim KPM BPSDM Provinsi Jawa Barat memiliki latar belakang IT ditambah lagi pada tahun 2018 Tim KPM Fokus untuk perbaikan kondisi WEB Diklat. Hal ini menjadi nilai positif terhadap kinerja KPM.

e) Lingkungan Fisik/Geografis

BPSDM Provinsi Jawa Barat berada kondisi lingkungan geografis dimana keadaan sarana dan prasana cukup baik.

Lebih lanjut Murpphy \& Cleveland (1990:26) menerangkan bahwa masing-masing aspek lingkungan tersebut cenderung mempengaruhi penilaian kinerja dalam beberapa cara. Namun beberapa memiliki dampak yang lebih langsung sedangkan yang lain memiliki dampak tidak langsung, tetapi tetap penting. Berdasarkan penjelasan Murphy \& Cleveland maka standar yang mendefinisikan kinerja baik dan buruk pada pekerjaan akan sangat dipengaruhi oleh aspek lingkungan.

\section{Kesimpulan}

Berdasarkan uraian hasil penelitian dan analisa pembahasan pada diskusi sebelumnya terdapat beberapa catatan penting untuk dapat direnungkan bersama. Penelitian ini telah mencoba untuk menjawab rumusan masalah penelitian tentang perencanaan kinerja komite penjamin mutu lembaga diklat pemerintah daerah. Adapun beberapa catatan penting tersebut terangkum dalam kesimpulan berikut ini:

a) Perencanaan Kinerja Tim Komite Penjamin Mutu BPSDM Provinsi Jawa Barat sudah memenuhi tahapan Perencanaan Kinerja menurut Robert Bacal. Namun yang menjadi kekurangan yakni belum adanya indikator kinerja. Peneliti menemukan bahwa Tim KPM BPSDM Provinsi Jawa Barat telah menggunakan salah satu konsep peningkatan mutu, yakni konsep mutu menurut Joseph Juran yang terkenal dengan istilah Trilogi Mutu.

b) Stakeholders yang terlibat dalam pembentukkan Tim KPM BPSDM Provinsi Jawa Barat baru melibatkan stakeholders internal dalam pembentukkan Tim KPM.

c) Tim KPM BPSDM Provinsi Jawa Barat dalam melaksanakan penjaminan mutu berkiblat pada pelaksanaan ISO dengan menggunakan Model Trilogi 
Juran. Dari hasil penelitian ditemukan bahwa, model tersebut sesuai dengan perencanaan kinerja yang diusung oleh Robert Bacal.

d) Potensi yang dimiliki oleh Tim KPM BPSDM Provinsi Jawa Barat berdasarkan Kats dan Kahn yang dikutip oleh Murphy and Cleveland (1990) dapat dilihat dari:

1. Nilai-nilai sosial

KPM BPSDM Provinsi Jawa Barat memiliki rasa memiliki terhadap BPSDM. Hal tersebut dilatarbelakangi oleh pengalaman mereka yang sudah pernah terlibat dan menjabat di BPSDM Provinsi Jawa Barat. Hal ini menjadi nilai positif terhadap kinerja KPM.

2. Lingkungan politik dan hukum

KPM Provinsi Jawa Barat memiliki dasar hukum yakni SK Kepala Badan Hal ini menjadi nilai positif terhadap kinerja KPM.

3. Lingkungan tenaga kerja

Formasi Tim KPM yang berjumlah lima orang menjadi tantangan besar untuk menjamin mutu diklat yang intensitas penyelenggaraanya cukup tinggi. Hal ini menjadi nilai negatif terhadap kinerja KPM.

4. Informasi/ lingkungan teknologi

Salah satu anggota tim KPM BPSDM Provinsi Jawa Barat memiliki latar belakang IT ditambah lagi pada tahun 2018 Tim KPM Fokus untuk perbaikan kondisi WEB Diklat. Hal ini menjadi nilai positif terhadap kinerja KPM.

5. Lingkungan fisik/geografis

BPSDM Provinsi Jawa Barat berada kondisi lingkungan geografis dimana keadaan sarana dan prasana cukup baik.

Dengan demikian disadari bahwa perlu adanya upaya perbaikan. Berikut ini beberapa saran peneliti berdasarkan rumusan masalah, rekomendasi untuk BPSDM Provinsi Jawa Barat dalam meningkatan Kinerja Komite Penjamin Mutu, diantaranya yakni:

a) Membuat perencanaan kinerja penjaminan mutu menggunakan Model Mutu Perencanaan Kinerja Tim KPM;

b) Menjalin komunikasi dan koordinasi dengan baik antar anggota KPM dengan pengelola dan penyelenggara diklat; dan

c) Menyiapkan perangkat kerja penjaminan mutu berupa Pembuatan dan Pelaksanaan SOP, Instrumen Penjaminan Mutu.

Untuk penelitian selanjutnya dilihat mengenai efektifitas keberadaan komite penjamin mutu lembaga diklat terhadap mutu penyelenggaraan diklat.

\section{Daftar Pustaka}

Amir, M. Faisal. (2015). Memahami Evaluasi Kinerja Karyawan: Konsep dan Penilaian Kinerja di Perusahaan. Jakarta: Mitra Wacana Media.

Le Breton, Preston P.., \& Henning, Dale Ansgar. (1961). Planning Theory. New Jersey, US: Prentice-Hall.

Bacal, Robert. (2002). Performance Management; Memberdayakan Karyawan, Meningkatkan Kinerja Melalui Umpan Balik, Mengukur Kinerja - Penerjemah Surya Dharma dan Yanuar Irawan. Jakarta: Gramedia.

Jabnoun, Naceur. (2004). An Implementation Model for Quality Assurance. In Asia Pasific Management Review, Vol. 9, No.1, pp.23-37.

Juran, Joseph M. (1998). Juran's Quality Handbook. McGraw-Hill, US.

Kunarjo. (2002). Perencanaan dan Pengendalian Program Pembangunan. Jakarta: UI Press.

LAN. (2017). Akreditasi Lembaga Diklat Kementrian/ Lembaga. Dapat diakses pada https://sipka.lan.go.id/accreditation. [Diakses pada 22 Juni 2018].

Larat, Fabrice. (2015). Internal and External Quality Control Mechanisms: Lessons Drawn from the Ecole Nationale d'Administration of France", in Allan Rosenbaum (Ed), "Standards of Excellence in Public Administration Training and Education". Slovak Republic: NISPACE Press.

Litman, Todd Alexander. (2013). Planning Principles and Practices. Dapat diakses pada http://www.vtpi.org/planning.pdf. [Diakses pada 2 Juni 2018].

Litman, Todd. (2003), Measuring Transportation: Traffic, Mobility and Accessibility. ITE Journal, Vol. 73, No. 10, pp.28-32.

Miles, Matthew B., A.Michael Huberman., \& Johnny Saldana. (2014). Qualitative Data Analysis: a Methods Sourcebook. USA: SAGE.

Muhandri, Thahja., \& Kadarisman, Darwin. (2006). Sistem Jaminan Mutu Pangan. Bogor: IPB Press.

Murphy, Kevin R., \& Cleveland, Jeanette N. (1990). Performance Appraisal: an Organizational Perspective. Massachusetts: Simon \& Schuster Inc.

Sedarmayanti. (2013). Reformasi Administrasi Publik, Reformasi Birokrasi, dan Kepemimpinan Masa Depan (Mewujudkan Pelayanan Prima dan Kepemerintahan yang Baik). Bandung: Refika Aditama.

Tunsiah, Siti. (2017). Evaluasi Peran Komite Penjamin Mutu Penyelenggaraan Diklat Prajabatan dan Kepemimpinan. Jurnal Analisis Kebijakan, Vol. 1, No. 2, pp.12-22. 